\title{
Corpos em deslocamento: sobre o percurso criativo \\ da obra de Carlos Vergara ${ }^{1}$
}

\author{
Renata Favarin Santini ${ }^{2}$
}

\section{Resumo}

Este artigo abriga algumas reflexões contidas em minha pesquisa de mestrado, referente à trajetória do artista Carlos Vergara. Neste texto, o enfoque é dado ao processo construtivo de três obras, São Miguel - Sagrado Coração, (Monotipia e pintura sobre lona crua), S.M. 4 (3D lenticular) e São Miguel - Piso VI (Monotipia sobre lona crua), iniciadas durante a intervenção do artista nas ruínas de São Miguel das Missões (2008). Como resultados, foi constatada a presença da linguagem fotográfica no processo dessas três obras, nas quais se evidenciam deslocamentos físicos. Quando deslocadas para o ambiente de exposição, essas obras sustentam tais deslocamentos, que se evidenciam por meio de monotipias. No entanto, a visualidade das obras muitas vezes encobre desdobramentos de outros deslocamentos, que se comprovam através da análise dos documentos de processo. Sendo assim, torna-se evidente a possibilidade de os deslocamentos contidos no processo das obras desagregarem sentido nas mesmas, possibilitando assim o surgimento de novos regimes de visibilidade.

Palavras-Chave: Carlos Vergara, processo, deslocamento do visível.

\begin{abstract}
This article has some points contained in my master's research, referring to the work of artist Carlos Vergara. In this paper, the focus is given to the construction process of three works, St. Michael - Sacred Heart (Monotype and painting on raw canvas) MS 4 (3D lenticular) and San Miguel - Level VI (Monotype on raw canvas), initiated during the intervention of the artist in the ruins of San Miguel Mission (2008). As results, it was confirmed the presence of photographic language in the process of these three works, in which physical movements are evident. When shifted to environmental exposure, these works hold such displacements, which are evidenced by monotypes. However, the visual works often covers developments from other dislocations, which prove through analysis of process documentation. Thus, it becomes evident the possibility of offsets contained in the disaggregate the works in the same direction, thus enabling the emergence of new regimes of visibility.
\end{abstract}

Key-words: Carlos Vergara, process of creation, displacement of visible.

\footnotetext{
${ }^{1} \mathrm{O}$ artigo refere-se à pesquisa de mestrado desenvolvida junto ao Programa de Pós-Graduação em Artes Visuais da UFSM sob orientação do Professor Ayrton Dutra Corrêa, a qual se constituiu de um estudo monográfico sobre a poética da obra do artista Carlos Vergara. O estudo contou com visitas às exposições realizadas no ano de 2009 em Porto Alegre, RS e Rio de Janeiro, RJ, além de encontros com o artista em ambas as exposições e em seu ateliê, no Rio de Janeiro, de onde foram consultados registros de seu processo criativo.

${ }^{2}$ Mestre em Artes Visuais PPGART/UFSM, na área de concentração Arte Contemporânea, linha de Pesquisa Arte e Visualidade. Bacharel e Licenciada em Desenho e Plástica (UFSM), com Especialização em Educação Ambiental.
} 


\section{Apresentação}

A presente pesquisa consiste em um estudo sobre a poética visual de Carlos Vergara ${ }^{3}$ (1941), na qual proponho um diálogo com seu processo de criação. Para isso, adoto três obras apresentadas na Exposição Sagrado Coração - Missão de São Miguel, no período de 23 de dezembro de 2008 a 15 de março de 2009, no Museu de Arte do Rio Grande do Sul Ado Malagoli, em Porto Alegre, RS. As mencionadas obras são: São Miguel Sagrado Coração, (Monotipia e pintura sobre lona crua), S.M. 4 (3D lenticular) e São Miguel - Piso VI (Monotipia sobre lona crua).

A pesquisa é fundamentada em leituras que perpassaram a História, Teoria e Crítica de Arte, constituindo deste modo um estudo monográfico sobre arte brasileira contemporânea, cujo enfoque é o processo construtivo da obra de arte. Dessa forma, julgo adequado reportar ao estudo desenvolvido por Cattani (2007) quanto à ocorrência de mestiçagens na arte contemporânea, alertando para os cruzamentos produtores de sentidos existentes no processo de instauração das obras. Foram os cruzamentos entre procedimentos usados por Carlos Vergara as bases para a construção deste trabalho.

Além disso, duas questões permearam o desenvolvimento da pesquisa: o deslocamento físico e a conseqüente apropriação do espaço pelo artista em seu processo criativo. A problemática proposta, deste modo, é a seguinte: De que maneira ocorre o deslocamento do visível/invisível na obra de Carlos Vergara? Ou seja, como o deslocamento físico do artista - ação de visitamento a determinados lugares -, e os possíveis deslocamentos contidos na sua poética, enquanto vestígio/indícios/sinais desses lugares, acontecem simultaneamente em seu processo de criação.

Tendo em vista a complexidade de um estudo sobre a poética de um artista que trabalha em caráter experimental, meu propósito foi de aproximação aos processos, por meio de documentos disponibilizados pelo artista e de seu testemunho oral e escrito. Nessas circunstâncias, procurei reunir as falas advindas da Crítica, da História e da Teoria da Arte, e de Carlos Vergara, a fim de engendrar minha própria perspectiva:

(...) abordar criticamente obras de arte é uma atividade que tem suas limitações, pois será sempre uma perspectiva "de fora", extrínseca à própria produção. O que sobre elas afirmamos habitualmente constrói-se pelos caminhos das conjeturas e

\footnotetext{
${ }^{3}$ Carlos Augusto Caminha Vergara dos Santos, artista nascido em Santa Maria, RS, em 29 de novembro de 1941. Iniciou sua participação no cenário artístico nacional em meados dos anos 1960 no Rio de Janeiro, onde reside até hoje. Nessa mesma época foi assistente e discípulo de Iberê Camargo, e selecionado para a VII Bienal Internacional de São Paulo. Desde então, vem trabalhando ativamente em diversas mídias, porém mantendo a pintura como atividade primordial. Desde o início dos anos 1990 vem assumindo uma postura viajante, praticando a incursão em diversas regiões do Brasil e exterior, nas quais realiza a técnica da monotipia.
} 
incertezas. Nunca estamos inseridos em seu real processo de engendramento, não participamos do ideário atuante do artista, tampouco dos sentimentos e emoções que compuseram seu processo produtivo. Nós o visualizamos mediante variados recursos auxiliares (...), tais como os relatos do artista e dados históricos ou bibliográficos, filmes e fotografias que acompanham seu trabalho, textos e informações diversas sobre as obras, sabendo que são apenas documentos que nos apóiam nessa tarefa (ZIELINSKY, 2003, p.97).

Além das colocações de Zielinsky, se tornam relevantes ainda as considerações de Salles (2009) no que se refere ao objeto de investigação que proponho na pesquisa:

Estamos conscientes de que não temos acesso direto ao fenômeno mental que os registros materializam, mas estes podem ser considerados a forma física através da qual esse fenômeno se manifesta. Não temos, portanto, o processo de criação em mãos, mas apenas alguns índices desse processo. São vestígios vistos como testemunho material de uma criação em processo (SALLES, 2009, p. 21).

O discernimento necessário quanto ao agrupamento das falas em suas especificidades foi sendo construído no decorrer da pesquisa, na medida em que me aproximava da poética do artista. Por essa razão, a necessidade de agrupar informações diversas e não pontuais.

Este artigo aborda o terceiro capítulo da pesquisa, intitulado Corpo em deslocamento: sobre o percurso criativo da obra de Carlos Vergara, no qual adentro nos procedimentos adotados pelo artista na elaboração da obra de arte, a partir das obras já nomeadas São

Miguel - Sagrado Coração, S.M. 4 e São Miguel - Piso VI. Busco contextualizar neste texto o conceito de deslocamento, incorporando o modo como o próprio artista percebe essa questão. Cecilia Almeida Salles (2006, 2009), e Rosane de Andrade (2002) embasam as relações com o processo, enquanto que Anne Cauquelin (2008) fundamenta as questões do deslocamento, e do visível.

\section{Deslocamentos durante o processo de pesquisa}

Como decorrência do interesse pela criação artística de Carlos Vergara, busquei uma aproximação aos procedimentos que tornaram essa construção possível. O deslocamento realizado por mim até São Miguel das Missões $^{4}$ foi importante na medida em que exercitou meu olhar para tal aproximação (Figuras 1 e 2 ):

\footnotetext{
${ }^{4}$ Visita realizada entre os dias 15 e 16 de fevereiro de 2009, ruínas de São Miguel das Missões, RS.
} 

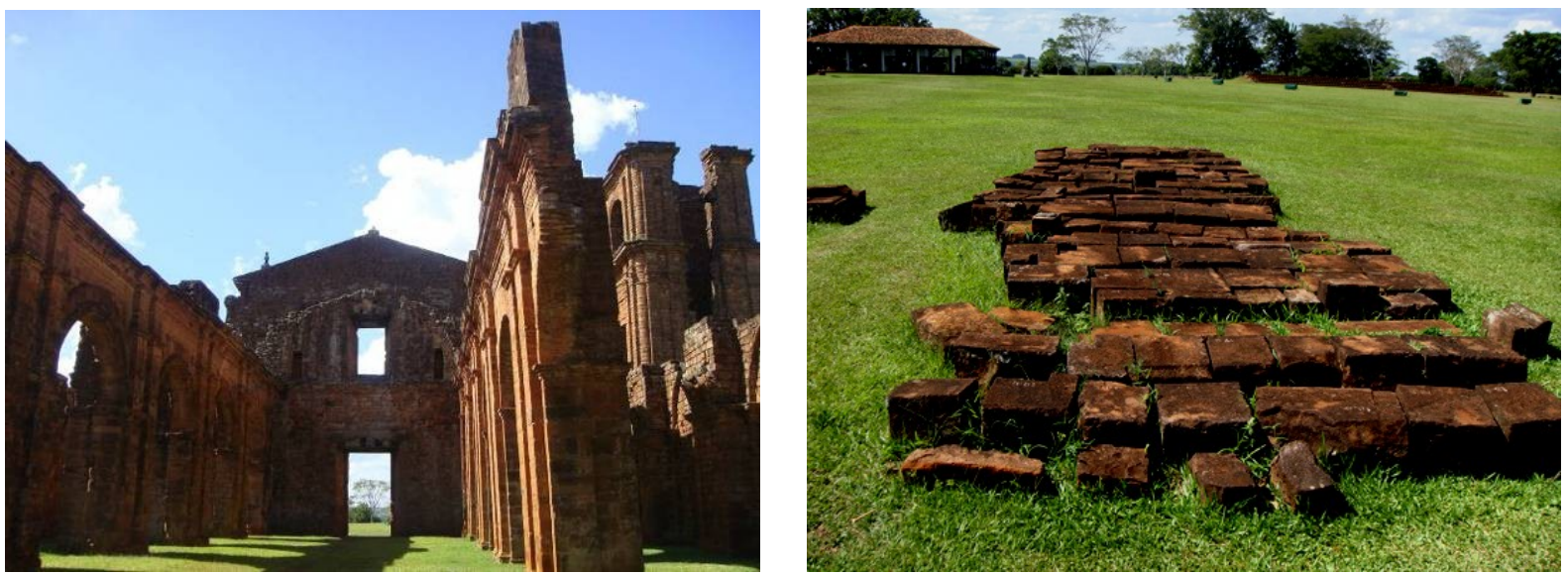

Figuras 1 e 2- Registros da visita às ruínas de São Miguel das Missões, RS.

Além deste, executei outros três deslocamentos: o primeiro se deu para a exposição Sagrado Coração - Missão de São Miguel ${ }^{5}$ (Figuras 3 e 4). Em seguida, após a visita a São Miguel, ocorreu meu primeiro encontro com o artista $^{6}$, e, finalmente, a visita ao seu ateliê ${ }^{7}$.
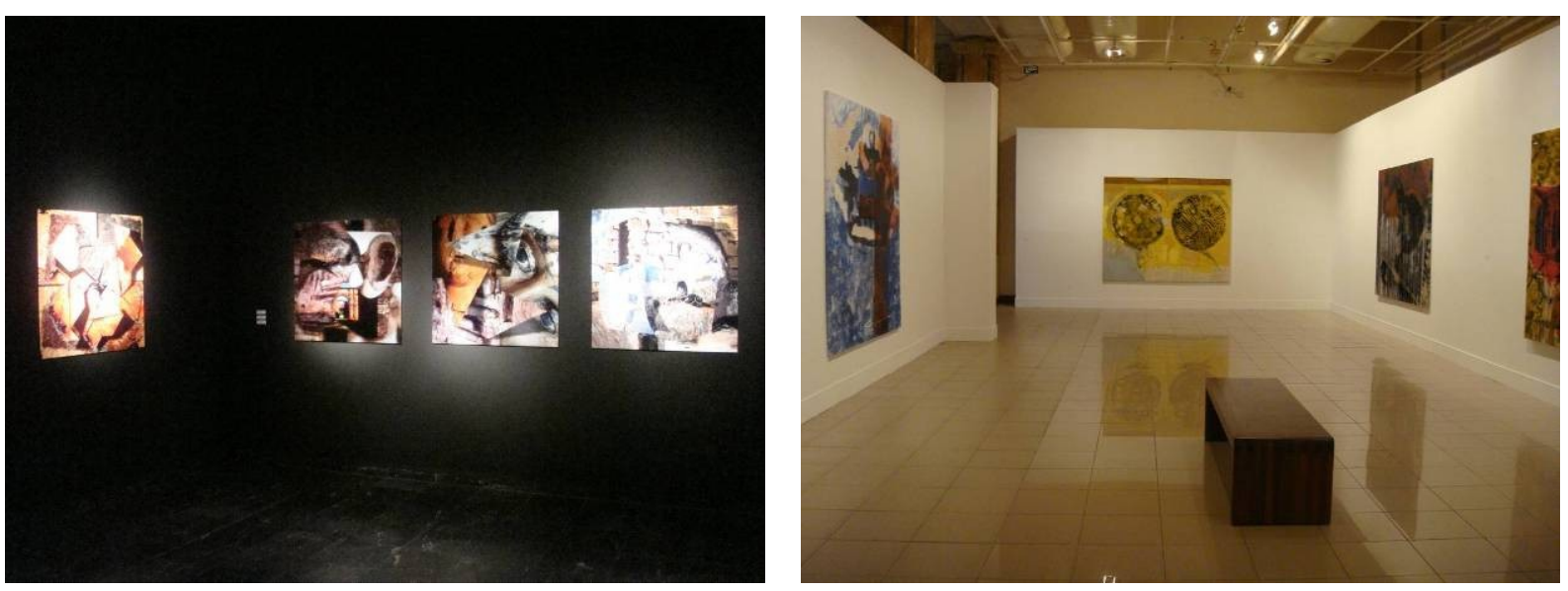

Figuras 3 e 4 - Registros da exposição Sagrado Coração - Missão de São Miguel

A atenção de Vergara por São Miguel das Missões foi recompensada por sua contemplação no Edital Arte e Patrimônio $/ 2007^{8}$, iniciativa do Ministério da Cultura e do Instituto do Patrimônio Histórico e Artístico Nacional (IPHAN). Vergara examinou a

\footnotetext{
${ }^{5}$ Visita realizada entre os dias 10 e 11 de janeiro de 2009, Museu de Arte do Rio Grande do Sul Ado Malagoli MARGS, Porto Alegre, RS.

${ }^{6}$ Encontro realizado entre os dias 15 e 16 de março de 2009 na cidade de Porto Alegre, RS. Nesta ocasião, se deu o encerramento da exposição Sagrado Coração- Missão de São Miguel.

${ }^{7}$ Visita realizada entre os dias 22 e 23 de outubro de 2009, Ateliê do artista em Santa Teresa e Museu de Arte Moderna do Rio de Janeiro, RJ. Registros no Anexo A.

${ }^{8}$ Sobre este edital, acessar: <http://www.artepatrimonio.org.br/arqs/layout_sagrado_coracao.pdf>
} 
missão jesuítica contada pelo Padre Antonio Sepp (1655-1733), o que o levou a conhecer profundamente como era a vida nas reduções, durante os séculos XVII e XVIII. Um "roteiro do olhar" começa a ser formado a partir dessa busca. O artista percorre o espaço ciente dos acontecimentos passados no lugar que será explorado, esse é o primeiro passo da sua conduta poética.

São Miguel oferece uma visão impactante do que foi a imponência de uma coletividade formada por jesuítas e guaranis, pela sua impressionante escala física, pela forma que foi preservada. Comprovei sua grandiosidade quando em janeiro de 2009 visitei pela primeira vez o lugar desta intervenção de Vergara, a qual considero um dos subsídios que contribuíram para minha aproximação à sua poética.

A ordem dos deslocamentos realizados não foi premeditada, sucederam-se de acordo com o surgimento das oportunidades de estes ocorrerem. A visita à exposição como deslocamento inicial foi significativa em razão de eu apresentar naquele momento uma visão incipiente sobre sua poética, e ao mesmo tempo, por constituir a essência de minha investigação: os trabalhos desenvolvidos em São Miguel. Isso contribuiu para que os movimentos seguintes fossem guiados por este ponto referente.

Os documentos aos quais tive acesso durante a visita ao seu ateliê reforçaram ainda mais meu interesse pelo processo construtivo de sua obra, fato que já ocorria durante a investigação de sua trajetória, na qual o procedimento é considerado uma marca ativa. Artista viajante, artista inquieto, artista favorável às experimentações. É notável que tais características atribuídas por parte da crítica à poética de Carlos Vergara estão ajustadas aos procedimentos com os quais o artista executa suas obras.

Desses documentos recolhidos no ateliê, defini por estabelecer um diálogo com os registros fotográficos, objetivando dessa forma me familiarizar do processo. Nesse caso, os registros concernem, em parte, a teia construtiva de algumas das obras expostas na exposição estudada.

\section{Corpos em deslocamento}

Os lugares/pretextos que condicionam a concepção artística na poética de Vergara são encontrados por meio do deslocamento/visitamento do artista. A obra se materializa na entrega ao deslocamento de si mesmo e também no deslocamento da obra, do lugar/pretexto para o ateliê (material), e do ateliê para o local de exposição (material). Contudo, a obra ainda arqueja em deslocamentos imateriais, invisíveis, os quais se 
revelam no seu interior, nos entremeios entre o que é pintura e o que é impressão, contaminada ainda pelo corpo que na tela foi firmado para abrigar seu molde.

No que diz respeito às abordagens encontradas sobre o deslocamento, existe uma disposição teórica no campo da arte que vem tratando deste conceito na arte contemporânea. Seu enfoque converge, em grande parte, para o deslocamento de objetos cotidianos para o lugar de exposição, de onde se atribui de forma unânime, à contribuição de Marcel Duchamp. Este foi o artista que, logo ao início do século XX, propunha a admissão de objetos de uso cotidiano num ambiente tradicionalmente destinado à exposição de obras de arte. A atitude rebelde de Duchamp seria então encarada como manifestação crítica com relação às convenções adotadas pelo regime de arte e à divulgação da produção artística. A obra pode ser qualquer coisa, mas numa hora determinada. O valor estaria no lugar e no tempo, e o autor não é mais a figura central na produção, ele é apenas aquele que mostra. Anne Cauquelin (2005, p. 118) destacou que em Duchamp, a intervenção do artista ao exibir um objeto banal em um espaço institucionalizado já consistiria num deslocamento, e sua assinatura, "acrescentando alguma coisa", seria um segundo deslocamento.

Nesse sentido, é possível demonstrar a ocorrência de um deslocamento físico, neste caso do objeto banal que ao ser locomovido de um espaço a outro "perde" suas funções e atributos originais, passando a compor um outro ambiente, onde as questões relevantes para sua discussão passariam a ser outras. Vazio de seu sentido original, apenas sua visualidade permanece. Mas o que estará ali e que não é visível? Nessa perda de funções originais que incidiria um segundo deslocamento, cuja concretização não se pode ver, exceto pelo seu vestígio: a assinatura do artista.

Carlos Vergara relata um deslocamento. Existem outros.

(...) No fundo, o trabalho de São Miguel é só um deslocamento. Está tudo lá. Esse deslocamento é o que provoca alguma coisa. Lá a pessoa vê uma série de coisas. Deslocado, vê outras. Por isso, sempre é importante lembrar-se da lição de Duchamp: o ready-made é deslocado para uma área sagrada, o que determina uma nova leitura. Esse tipo de jogo que abriu a arte para novas possibilidades, com outras coisas além da habilidade manual'.

O deslocamento imaterial contido na obra de Vergara também está num vestígio. Esta marca provém do deslocamento material que se revela no processo construtivo da obra de arte, viabilizado pela monotipia extraída dos lugares explorados pelo artista. Adotei

\footnotetext{
${ }^{9}$ Depoimento do artista à autora em 15/03/2009, na cidade de Porto Alegre.
} 
para este caso um lugar específico, as ruínas de São Miguel das Missões, situadas no Rio Grande do Sul, um dos últimos lugares a ser explorados pelo artista. Em 2002, Carlos Vergara se encontrava imbuído pela idéia de intervir em São Miguel, onde mais tarde realizaria uma oficina com outros artistas convidados como parte integrante da sua exposição retrospectiva realizada no Santander Cultural, Porto Alegre, em 2003:

(...) tenho vontade de mergulhar nas Missões Jesuíticas aqui do Rio Grande do Sul. E isso é uma coisa muito pessoal. Todo mundo me fala daquelas terras vermelhas, e eu nunca fui lá, só conheço fotografias. Eu teria o maior interesse em fazer coisas lá, assim como já fiz trabalhos em Diamantina, em Ouro Preto, no Pantanal, em Goiás Velho, em Pirinópolis. É levar o olhar e pegar uma coisa que seja específica, que foi feita no lugar, mas que pode ir pra outro lugar, para um museu, por exemplo, e adquirir uma outra instância. Na verdade, a pintura às vezes está feita, está na natureza e eu apenas a retiro do lugar, como um sudário ${ }^{10}$.

Os exemplos procedentes da Land art apresentam-se como possibilidades de deslocamentos na arte contemporânea (CAUQUELIN, 2008). Transporte de materiais diversos, e em quantidades elevadas, tais como o basalto, terra e pedras, executado por artistas como Robert Smithson e Michael Heizer. Os deslocamentos, nestes casos particulares, dizem respeito ao local em que a obra é exposta, tornando imaterial sua constatação no ambiente de um museu ou galeria de arte. O lugar da obra residiria dessa maneira nos espaços naturais. Já no que se refere ao processo de Vergara, ao invés do material constituir a obra, o deslocamento da terra (pigmento) do lugar está contida nela.

Desde os capítulos anteriores, atento para a disponibilidade de Vergara para o outro, tendo ele mesmo admitido esta condição ao afirmar que: $O$ assunto do meu trabalho é o mundo, as coisas, entender o mundo, tentar ver coisas, tentar interpretar coisas e destrinchar questões ${ }^{11}$. O que Vergara tem feito nessas inserções por territórios brasileiros e por outros lugares é a exteriorização do seu deslumbramento pelo outro. No caso de São Miguel, refiro-me ao arrebatamento inicial a que todos passamos quando visitamos o lugar, seguido da busca por conhecer mais sobre o que lá se passou. Assemelha-se ao conhecer antropológico, contudo sem a intenção de descrever o outro. A intenção aqui é pura visualidade, diz respeito às questões do ver. Mas a disponibilidade pelo diferente existe, na medida em que expressa o desejo intenso de experimentação do artista.

\footnotetext{
${ }^{10}$ Um inquieto convicto, Entrevista em 16 de janeiro de 2002, concedida à Revista da Fundação Iberê Camargo, disponível em <http://www.iberecamargo.org.br/content/revista_nova/entrevista_integra.asp?id=21>

${ }^{11}$ Entrevista cedida à Bianca Ramoneda para o Programa Starte - canal de TV a cabo Globo News -, no dia 22 de outubro de 2009, no ateliê do artista em Santa Teresa, Rio de Janeiro.
} 
No que diz respeito à análise e discussão dos dados levantados, foi constatada a utilização da fotografia durante o processo construtivo das três obras selecionadas, porém com propósitos distintos. Na obra S.M. 4, se encontra incorporada ao trabalho final. Já na obra São Miguel - Piso VI, a fotografia revela partes da ação desenvolvida durante o processo construtivo da monotipia. No que se refere ao processo de São Miguel - Sagrado Coração, é o elemento que possibilita revelar a mistura de materiais e técnicas. Essas comprovações revelaram entrecruzamentos com os quais pretendi refletir sobre a problemática proposta ao início da pesquisa.

A fim de justificar a importância de um olhar sobre esses registros, recorro às premissas apresentadas por Salles (2006, p. 13) em seu estudo sobre o processo de construção da obra de arte, no qual afirma que "na relação entre esses registros e a obra entregue ao público, encontramos um pensamento em construção". Esta seria uma maneira de se aproximar dessas obras, mesmo que esses registros não abranjam todo o projeto poético do artista. Salles (2006, p. 16) acredita que essas questões "necessitam de um olhar que seja capaz de abarcar o movimento, dado que leituras de objetos estáticos não se mostram satisfatórias ou eficientes". Vergara se utiliza ainda de mídias digitais, o que reforça a exigência de novas abordagens como esta apontada por Salles (2006).

Os registros fotográficos realizados durante o deslocamento físico do artista auxiliam ainda para que a obra possa ser desenvolvida fora do contexto do lugar visitado. Este é o caso da inclusão de novas mídias na poética da obra, que ocorre no processo construtivo de S.M. 4. Assim sendo, as obras referidas se constroem nesse deslocamento que transcende a operação física do artista, entre diferentes meios, da monotipia à pintura; ou ainda, da fotografia ao programa de computador. Nesse sentido, torno a mencionar as colocações de Salles (2006) sobre o caráter dinâmico da criação artística, se apresentando em um percurso contínuo de inacabamento, "como uma possível versão do que pode vir a ser ainda modificado" (Ibid., p. 20).

As contribuições de Salles são evidentes, na medida em que,

os artistas não fazem seus registros, necessariamente, nas linguagens nas quais as obras se concretizarão; estes apontamentos, quando necessário, passam por traduções ou passagens para outros códigos" (SALLES, 2006, p. 95).

Os registros fotográficos apresentados nesta pesquisa como documentos deixados pelo artista, em conformidade com Salles (2006), constituem, em alguns casos, o olhar curioso do artista, ao selecionar através da câmera fotográfica os lugares que chamaram sua atenção, e em outros casos, o registro do processo de construção de suas 
monotipias. Também se percebe que os enquadramentos selecionados por Vergara constituem possibilidades de futuros trabalhos, como o que ocorre com a seleção para os trabalhos em 3D lenticular.

Esse olhar curioso se configura na mistura entre o visitante que se vê impactado pela monumentalidade da arquitetura do lugar, e o artista que ali pretende iniciar uma intervenção. Nesse sentido, as reflexões de Andrade (2002), revelam essa mistura de um olhar de descoberta e de criação.

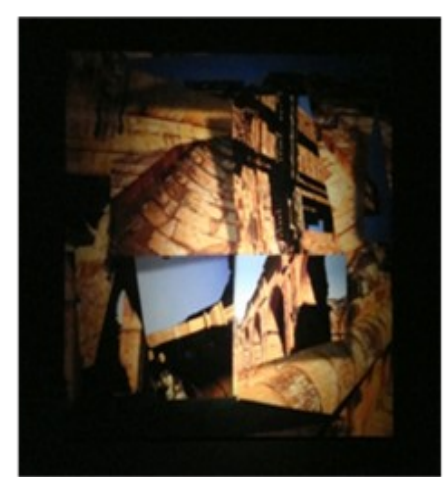

S.M. 42008

$3 \mathrm{D}$ lenticular

$100 \times 100 \mathrm{~cm}$

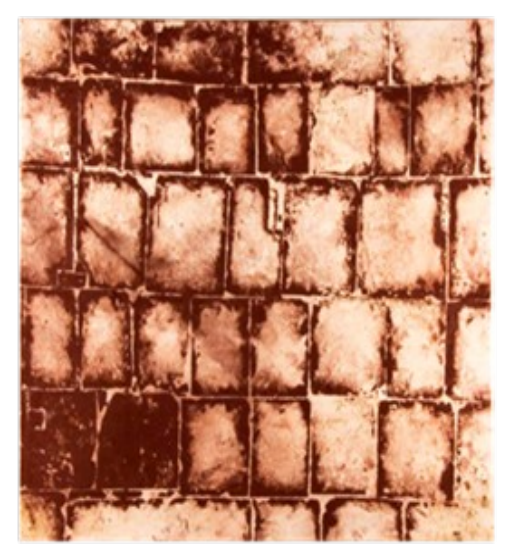

São Miguel - Piso VI 2008

Monotipia sobre lona crua $275 \times 290 \mathrm{~cm}$

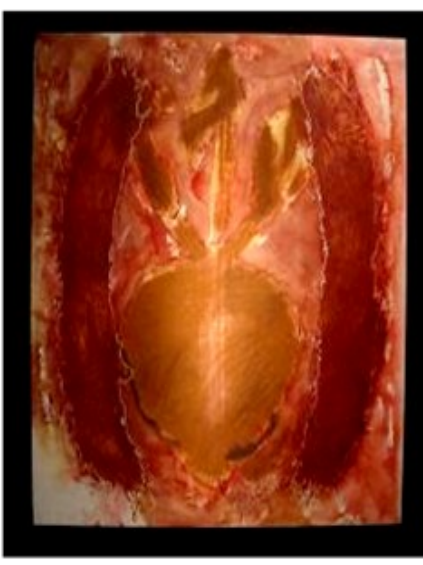

São Miguel - Sagrado Coração 2008 Monotipia e pintura sobre lona crua $215 \times 190 \mathrm{~cm}$

Figura 5 - Obras selecionadas para análise quanto ao processo

Na obra S.M. 4, a fotografia auxilia o artista a compor as transformações a partir dela, operando num primeiro momento como o registro de sua percepção, para posteriormente ser utilizada como parte integrante e fundamental da obra. Mais do que um registro documental, neste caso a fotografia é ato que constitui a obra de arte. A fotografia sofre transformações na medida em que se desloca no processo.
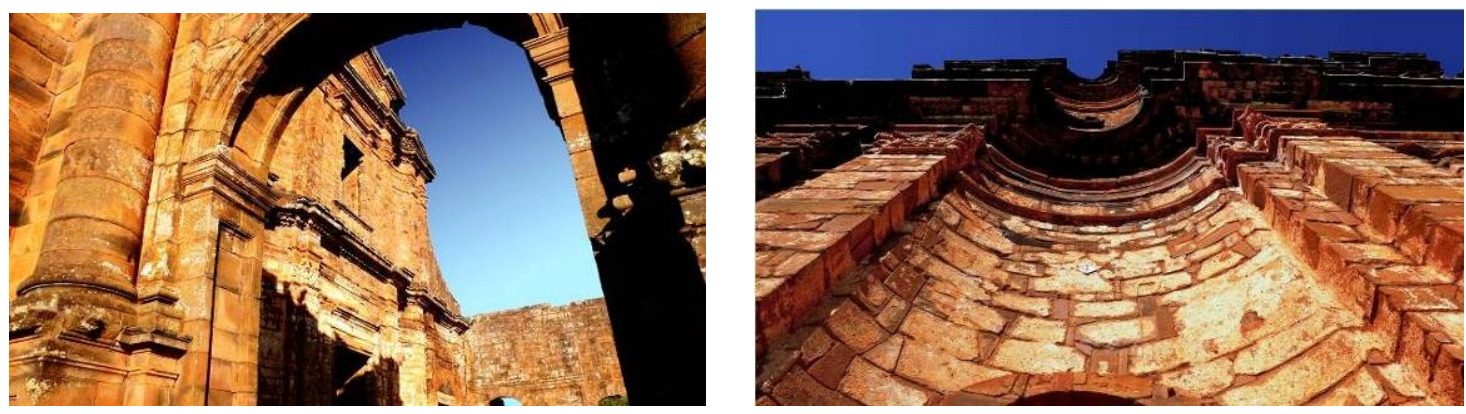

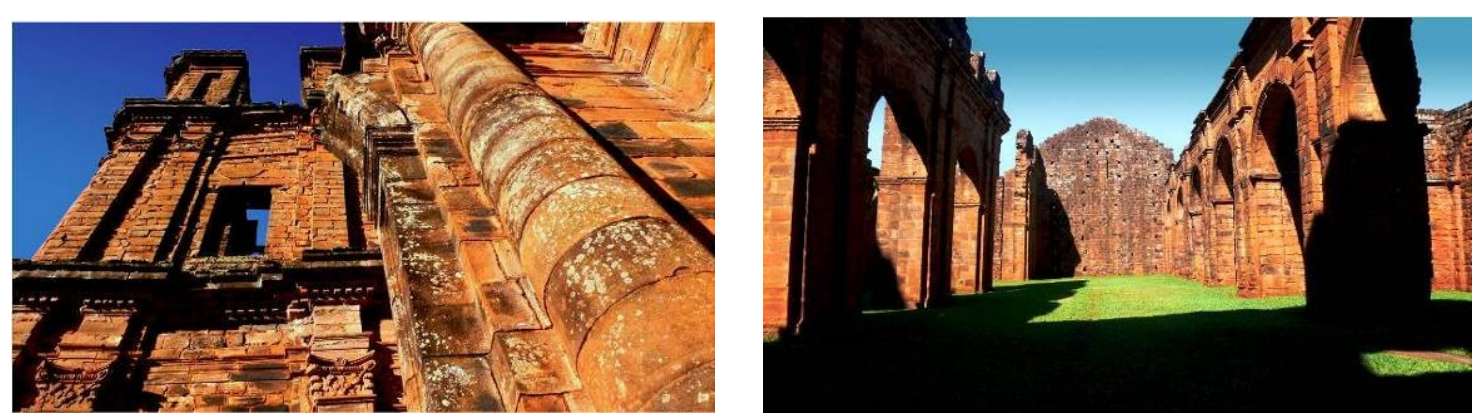

Figuras 6, 7, 8 e 9 - Fotografias utilizadas para elaboração da obra S.M. 4. Arquivo do artista

As imagens em 3D lenticular partem de fotografias, que são recortadas pelo artista formando uma nova imagem a partir da junção de quatro fotos. A nova imagem construída é aplicada em um software para depois ser impresso em linhas de um milímetro. Posteriormente, se aplica uma lente ondulada, de onde se espera adquirir um efeito em relevo.

Neste caso, a imagem computacional é a expressão da digitalização, ou seja, da conversão de imagens fotográficas para a imagem digital por processos de numeração (ARANTES, 2005).

(...) fotografia recortada, sobreposta, encaixada, e uma rolha para fazer um relevo, é colado com fita atrás. Na verdade é uma maquete, que já é $3 \mathrm{D}$, só que real, e que depois se transformará em um 3D virtual. É uma tecnologia nova e ao mesmo tempo velha. Antigamente faziam aqueles chaveirinhos, e que agora conseguiram desenvolver um software para produzir grande ${ }^{12}$.
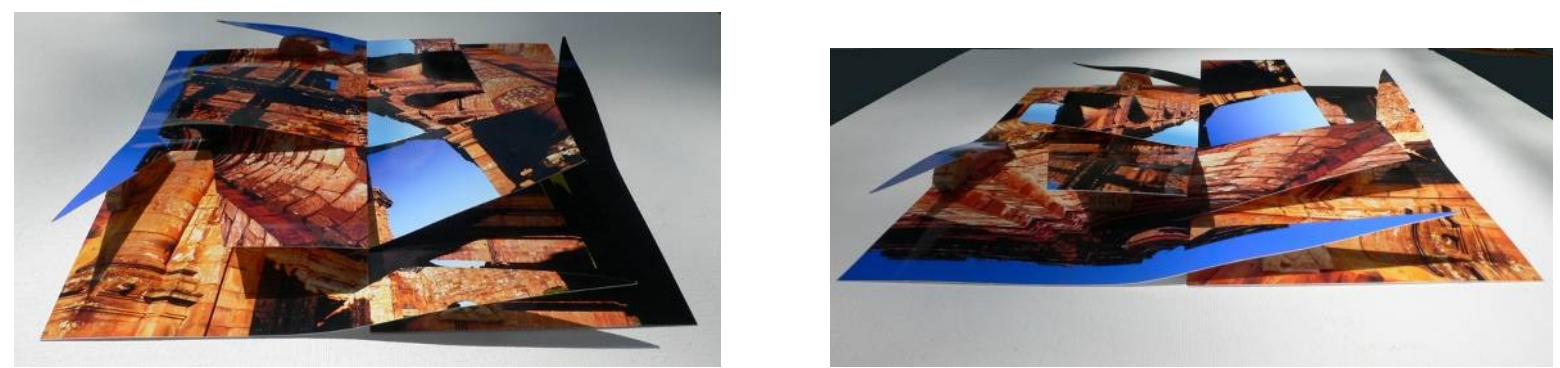

Figuras 10 e 11 - Maquete digitalizada em diferentes pontos de vista

\section{Arquivo do artista}

\footnotetext{
${ }^{12}$ Entrevista cedida à Bianca Ramoneda para o Programa Starte - canal de TV a cabo Globo News -, no dia 22 de outubro de 2009, no ateliê do artista em Santa Teresa, Rio de Janeiro.
} 
No que se refere à obra São Miguel - Sagrado Coração, a primeira monotipia é reproduzida em escala ampliada para causar o efeito pretendido pelo artista. A ampliação almejada é impressa em plotter para depois sofrer intervenção manual.
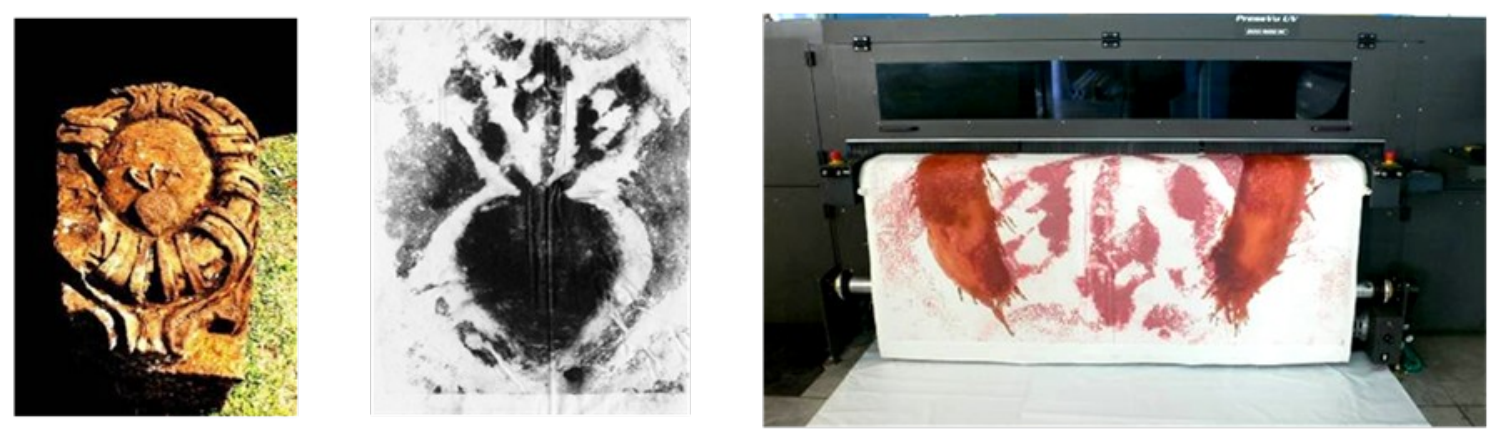

Figura 12 - Registros de processo da obra São Miguel - Sagrado Coração Arquivo do artista

Essa primeira monotipia é feita sobre um lenço. Esses lenços, segundo o artista, possuem papel significativo, pois estão diretamente relacionados à sua conduta de artista viajante. Suas palavras levam à compreensão dos modos como o ambiente que envolve as criações é processado pelo artista:

(...) O lenço é um lenço de bolso, de um viajante que tem um pedaço de pano no bolso e que recolhe uma coisinha, uma mancha, uma pedra, uma folha. E que eu espero que possa, deslocado para um outro lugar, junto com as fotos que eu faço, junto com os trabalhos mais elaborados que eu faço depois, montar um corpo de uma outra viagem sem sair do lugar.

O interesse do artista pelo intercâmbio entre a sua pintura e outras mídias propicia também o intercâmbio de idéias. A interação entre diferentes meios, que se torna evidente nas imagens de processo das obras São Miguel - Sagrado Coração e S.M. 4 revela a desestruturação da idéia de autoria única do artista sobre sua obra. Sendo assim, o artista age em meio à multiplicidade de interações e diálogos, submetendo a obra a deslocamentos entre linguagens.

São Miguel - Piso VI apresenta um vestígio do piso das ruínas de São Miguel. Nesta obra, não existe a pintura pelas mãos do artista, é o pigmento "peneirado" sobre as pedras que constitui a sua ação, seguida da pressão do corpo para fixar o pigmento na lona crua, onde o desenho que compõe o piso é delimitado pela ação da cor. 
No processo construtivo desta obra, a fotografia representa mais que um registro documental. Trata-se do ato fotográfico, da relação estreita com o seu referente, no caso das monotipias, do recorte espaço-temporal do momento do "isto foi" (FERREIRA, 2010, p. 13$)^{13}$.
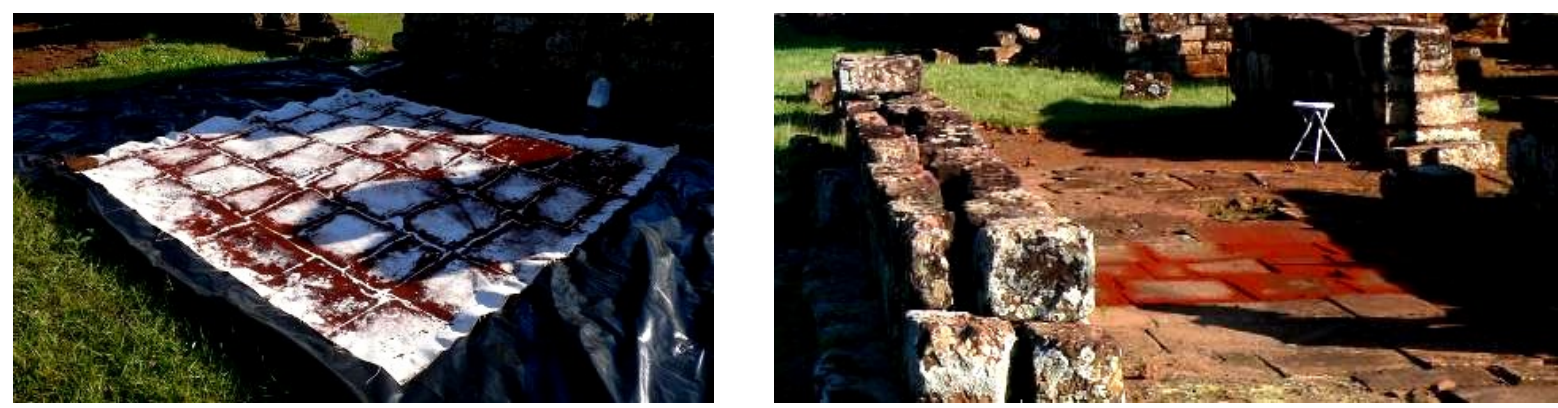

Figura 13, 14, 15 - Registros de processo da obra São Miguel - Piso VI Arquivo do artista

Verifica-se, dessa forma, que o registro revela muito sobre a obra. A fotografia desvenda informações sobre o lugar, do encontro da tela com o piso de São Miguel. Nesse sentido, tudo é corpo, e o que é revelado a partir do processo adquire caráter de mobilidade, entre o que antes foi corpo e depois se tornou vestígio, entre o que é visível e o que se apaga. Com isso, "a foto é a testemunha da existência do trabalho e sua operação se confunde com o mesmo" (FREIRE, 1999, p. 95).

\section{Considerações Finais}

A monotipia é um processo de impressão espontâneo no qual o artista trabalha livremente, sem normas. Carlos Vergara a executa, conforme já dito anteriormente, de acordo com o seu deslocamento físico, e com as coisas visíveis por ele. Merleau-Ponty, em seu escrito intitulado $O$ olho e o espírito, interroga a visão e a pintura. Suas reflexões abrangem o movimento do corpo - o deslocamento - e a visão. Sua contribuição é valiosa no que diz respeito a esse ato de pintar, e das coisas que a envolvem, a visão, o movimento do mundo, embate do mundo e do corpo. Segundo ele, todos os deslocamentos "estão reportados ao mapa do visível" (MERLEAU-PONTY, 2004, p.16). Para o autor, o corpo se move na medida em que a visão amadurece. O corpo visível e móvel está preso no tecido do mundo, e a sua visão se faz do meio das coisas.

Instrumento que se move por si mesmo, meio que inventa seus fins, o olho é aquilo que foi sensibilizado por um certo impacto do

\footnotetext{
${ }^{13}$ Fragmento do texto produzido para ocasião da exposição Carlos Vergara: uma outra energia silenciosa, com curadoria de George Kornis. De 12 de novembro de 2009 a 15 de março de 2010, MAM - RJ.
} 
mundo e o restitui ao visível pelos traços da mão. Não importa a civilização em que surja, e as crenças, os motivos, os pensamentos, as cerimônias que a envolvam, e ainda que pareça votada a outra coisa, de Lascaux até hoje, pura ou impura, figurativa ou não, a pintura jamais celebra outro enigma senão o da visibilidade (MERLEAU-PONTY, 2004, p. 20).

Vergara se mostra sensível às coisas do mundo, e delas muitas vezes se apropria. Segundo Luiz Camillo Osório (2008, p. 119), "é uma produção que está ainda ligada a um corpo, ainda está ligada à mão. Esse tempo do corpo e esse tempo da mão de alguma maneira passam para o olhar também. Por isso é um tempo mais ocioso, mais lento".

Vergara se deixa impregnar pelo visível, um mundo disponível que, através de sua criação e de um olhar atento sobre ela, pode nos revelar invisíveis que a habitam. Essa experiência - de olhar-pensar - não é pragmática, e sim a soma de uma práxis com a percepção de uma ação. Com isso, minha experiência do visitamento ao lugar também visitado pelo artista foi determinante para criar relações de significados com os processos relatados pelo artista e pelas imagens que os descrevem. Por meio de seus trabalhos, Vergara mostra-se "testemunha de uma realidade ou de uma realização que a sua linguagem produz e reflete" (FRANCA, 2006, p. 191). Ao me aproximar desta realidade, me aproximo de sua criação.

Com o auxílio de olhos de estrangeiro, ele nos leva a ver o diferente e, no diferente, a emoção de ser diferente, a viajar em nossa própria cultura e a conhecer um pouco de nos mesmos: eis a função de um etnógrafo, um pesquisador, um investigador e um artista (ANDRADE, 2002, p. 19).

O deslocamento do visível na obra ocorre através da monotipia, a única impressão do corpo existente no lugar apropriado pelo artista. Esse vestígio é, portanto, a sobra visível do corpo apropriado durante o processo. A tela se "acomoda" sobre o corpo, e dele extrai sua feição. Depois, quando já se adicionou outras formas de visibilidade, e quando a tela já se afastou do lugar que contém o corpo sobre o qual se acomodou, o deslocamento é invisível: a feição que ali se apresenta equivalente ao corpo na verdade não o abriga. Será um olhar desgarrado, livre de convenções, que responderá por essa condução imperceptível pelo olho, esse, o deslocamento invisível.

Nos cruzamentos entre linguagens e elementos que compõem origens diversas, é possível estabelecer a produção de sentidos, tanto no que se refere aos processos de 
produção das obras, quanto na instauração das mesmas, nos quais residem os deslocamentos tratados nesta pesquisa.

Vê-se, com efeito, que a mistura mantém as particularidades que reafirmam a ligação das monotipias com o lugar originário, neste caso, as ruínas de São Miguel das Missões. Tal mistura contempla o entrecruzamento de linguagens, materiais, maneira de intervir sobre a obra durante seu percurso criativo, e que se mantém latente na obra.

Sendo assim, a pesquisa se deu de maneira a tratar primeiramente do artista como pessoa, para então conhecer sua obra, e, finalmente, perceber como ela se materializa. Com isso, o objetivo deste trabalho foi oferecer um olhar sobre a arte contemporânea brasileira através da produção de Carlos Vergara, considerando ainda as particularidades do artista como indivíduo sensível às coisas visíveis, num desejo constante de experimentação que se renova continuamente.

Considero que os deslocamentos são múltiplos. Assim como o artista se desloca em sua existência, sua obra também se desloca no tempo e no espaço, adquirindo a cada nova exposição ao público novos significados, para além dos deslocamentos do processo.

\section{Referências}

ANDRADE, Rosane de. Fotografia e antropologia: olhares fora-dentro. São Paulo: Estação Liberdade, EDUC, 2002.

ARANTES, Priscila. Arte e mídia: perspectivas da estática digital. São Paulo: Senac São Paulo, 2005.

CATTANI, Icleia Borsa (org.). Mestiçagens na arte contemporânea. Porto Alegre: Editora da UFRGS, 2007.

CAUQUELIN, Anne. Arte contemporânea: uma introdução. São Paulo: Martins, 2005.

Anne. Freqüentar os incorporais: contribuição a uma teoria da arte contemporânea. São Paulo: Martins, 2008.

FERREIRA, Glória. Riscos e chances. In: VERGARA, Carlos. A dimensão gráfica: uma outra energia silenciosa. Rio de Janeiro: Aeroplano, 2009.

FRANCA, Patricia. O lugar da Imagem. In: NAZARIO, L.; FRANCA, P.(orgs.) Concepções contemporâneas da arte. Belo Horizonte: Editora UFMG, 2006. 
FREIRE, Cristina. Poéticas do processo: arte conceitual no museu. São Paulo: Editora Iluminuras, 1999.

MERLEAU-PONTY, Maurice. O olho e o espírito. São Paulo: Cosac \& Naify, 2004.

SALLES, Cecilia. Redes da criação: construção da obra de arte. Vinhedo, SP: Editora Horizonte, 2006.

Gesto inacabado: processo de criação artística. 4 ed. São Paulo: FAPESP:

Annablume, 2009.

OSÓRIO, Luiz Camilo. Entrevistas. Realizado por Paulo Sergio Duarte. Opus: 2008. CDRom. In: DUARTE, Paulo Sergio. Arte brasileira contemporânea: um prelúdio. Rio de Janeiro: Silvia Roesler Edições de Arte, 2008.

ZIELINSKY, MÔNICA. A pintura de Iberê Camargo: um processo para sempre inacabado. In: SALZSTEIN, Sônia (org.). Diálogos com Iberê Camargo. São Paulo: Cosac \& Naify, 2003. 